\title{
LA IGNOTA ACCIÓN DE REGRESO DE LA ADMINISTRACIÓN EN LA ERA DE LA TRANSPARENCIA, LA EFICIENCIA Y LA RESPONSABILIDAD
}

\author{
Carlos Saura Fructuoso \\ Profesor de Derecho Administrativo \\ Universidad Complutense de Madrid \\ c.saura@der.ucm.es
}

SUMARIO

1.- Contexto de la acción a analizar

2.- La acción de regreso o repetición de la Administración frente a las autoridades y personal a su servicio. Concepto y regulación actual

3.- Problemas derivados de la actual configuración de la acción

4.- La acción de regreso en los Proyectos de Ley de Régimen Jurídico del Sector Público y de Ley de Procedimiento Administrativo Común de las Administraciones Públicas

5.- Propuestas y conclusión

\section{CONTEXTO DE LA ACCIÓN A ANALIZAR}

La acción de regreso de la Administración respecto a su personal no existe.

Quizás sea esta la forma más sincera de empezar el breve estudio que nos disponemos a desarrollar, pues un análisis de su eficacia y operatividad así lo corrobora.

Y no es porque no sea un instrumento útil. Más bien diríamos que en la actual coyuntura resulta hasta vital.

Entonces, ¿a qué se debe la rotundidad de la anterior afirmación? Dedicaremos las siguientes páginas a intentar explicarlo. No obstante, creemos fundamental referirnos previamente a una serie de cuestiones.

El análisis de un posible cambio normativo de cierta entidad, como el que podría llegar a producirse si se aprueban los Proyectos de “Ley de Régimen Jurídico del Sector Público”, por una parte, y de "Ley de Procedimiento Administrativo Común”, por otra, debe tener en cuenta una premisa fundamental, que consiste en preguntarnos qué tipo de Administración necesitamos en el contexto actual.

Como se indica en la propia rúbrica de este trabajo, los últimos cambios normativos de calado que en los últimos tiempos se han producido en el seno de la Administración pivotan en torno a tres conceptos fundamentales: Transparencia, eficiencia y responsabilidad'.

Sin ánimo de extendernos en esta cuestión, lo que parece claro e incontestable es que la función de administrar debe adaptarse a un mundo más rápido, más atento y, en definitiva, más exigente.

1 Se podrían citar en este punto multitud de normativa relevante, por lo que sólo referenciamos las principales: LO 2/2012, de 27 de abril, de Estabilidad Presupuestaria y Sostenibilidad Financiera; Acuerdo del Consejo de Ministros de 26 de octubre de 2012 , por el que se crea la "Comisión para la Reforma de las Administraciones Públicas" (CORA); Ley 19/2013, de 9 de diciembre, de Transparencia, Acceso a la Información Pública y Buen Gobierno; Ley 27/2013, de 27 de diciembre, de Racionalización y Sostenibilidad de la Administración Local; Ley 15/2014, de 16 de septiembre, de Racionalización del Sector Público y otras medidas de Reforma Administrativa; entre otras. 
Así, desde el punto de vista de la Administración, como instrumento para la realización de las funciones del Estado en su conjunto debe adaptarse a las nuevas fórmulas de comunicación existentes (como el adjetivo "electrónico/a" bien se encarga de recordarnos hasta la saciedad en los citados Proyectos de Ley), dando la posibilidad de conocer la mayor cantidad de datos posible acerca de su efectivo funcionamiento, fomentando la participación ciudadana, y facilitando de esta manera la rendición de cuentas del engranaje administrativo. Todos estos extremos se han condensado en célebres conceptos anglosajones como los de "open government" o "accountability".

Pero desde la otra cara de la moneda, principalmente la ciudadanía, ahora más que nunca va dejando de tener progresivamente esa actitud pasiva que se identificaba con la concepción clásica de "administrado", siendo un agente más en la correcta fiscalización del actuar público.

Y ello no sólo debe concebirse ya desde el punto de vista del asociacionismo que caracteriza a la denominada "sociedad civil organizada" (ex art. 22 de la Constitución Española), sino desde el plano puramente individual, pues progresivamente se va aumentando el catálogo de derechos que los ciudadanos pueden ejercitar en sus relaciones con la Administración, perdiendo poco a poco el carácter meramente programático².

Por tanto, en el seno de una sociedad cada vez más informada y democráticamente más exigente (como se ha demostrado con el actual panorama político), el tema que vamos a tratar brevemente adquiere una especial relevancia, pues se centra precisamente en la depuración de responsabilidad, la eficacia y, en definitiva, la obtención de una justicia material o efectiva ${ }^{3}$.

Ahora bien, lo más curioso y reseñable en el supuesto que vamos a tratar es que, al contrario de lo que se pudiera pensar, la base técnica y jurídica para dar cumplimiento a estos objetivos no proviene de las numerosas reformas normativas operadas al albor principalmente de la crisis económica de 2007-2008, sino que estos instrumentos se encuentran disponibles desde hace ya bastante tiempo; concretamente desde el año 1992.

Es por ello que a continuación intentaremos comprender su práctica inacción en más de 16 años.

\section{LA ACCIÓN DE REGRESO O REPETICIÓN DE LA ADMINISTRACIÓN FRENTE A LAS AUTORIDADES Y PERSONAL A SU SERVICIO. CONCEPTO Y REGULACIÓN ACTUAL}

Comenzando propiamente por una definición de la acción de regreso o de repetición, sería aquélla en virtud de la cual la Administración que ha debido indemnizar por una lesión cometida por las autoridades o personal a su servicio, pueda posteriormente repercutir el montante satisfecho por tal concepto a los mencionados sujetos, que en definitiva son los verdaderos responsables materiales del daño.

Esta acción tendría como fin el restablecimiento de la situación e indemnidad patrimonial de la Administración, a la vez que se evita que el contribuyente deba soportar el perjuicio que ha cometido un sujeto en particular e identificable.

Debemos tener en cuenta que esta responsabilidad patrimonial será independiente y acumulable a la responsabilidad disciplinaria ${ }^{4}$ y a la responsabilidad penal que eventualmente pudiera derivarse.

En la actualidad, la propia base de la acción de regreso la encontramos en el art. 35 j) de la Ley 30/92, que establece expresamente como derecho de los ciudadanos "exigir las responsabilidades de las Administraciones Públicas y del personal a su servicio, cuando así corresponda legalmente".

2 A tal efecto se puede citar como claro ejemplo el “Derecho de Buena Administración” en el seno de la Unión Europea, que ha supuesto dotar de un auténtico instrumento de garantías para el ciudadano que entabla relaciones con la Administración Europea, tanto desde una vertiente pasiva como desde una vertiente activa. Para un análisis detallado del mismo, vid. mi trabajo "El derecho de buena administración y el "due process" administrativo europeo", en Procedimiento Administrativo Europeo, Pp. 317 y ss., Civitas, Madrid, 2012.

3 Estableciendo el art. 3 de la Ley 30/92 como principios generales la eficiencia, transparencia y participación ciudadana, el art. 35 del mismo texto legal dispone expresamente como derechos de los ciudadanos exigibles ante las Administraciones Públicas el acceso a la información pública, archivos y registros, y el derecho a exigir responsabilidades de las Administraciones y del personal a su servicio.

4 En estos casos, no supone lo mismo emprender sanciones disciplinarias que la exigencia de toda una responsabilidad patrimonial por vía del ejercicio de la acción de regreso, ya que las sanciones pueden conllevar una multa nada satisfactoria en comparación al montante detraído en concepto de indemnización, o una simple suspensión temporal (muy temporal en ocasiones) del ejercicio de las funciones.

De hecho, a menudo se confunde (o se quiere confundir) el uso de ambas medidas, que atienden a realidades distintas: Con la responsabilidad patrimonial se repercute en el infractor material la cuantía indemnizatoria abonada por la Administración pagadora. Con la responsabilidad disciplinaria la retribución de la conducta no deseada y realizada por el empleado público, ejercitando de esta manera el empleador público las facultades de dirección, vigilancia e inspección en el curso de su actividad.

Por lo tanto, existe la tendencia a "subsumir" el resarcimiento de la responsabilidad patrimonial de la autoridad o personal público a la adopción de medidas disciplinarias, que en muchos casos tienen carácter limitado o "benévolo" en atención al perjuicio causado, para de esta manera dar una cierta impresión de diligencia por parte de la Administración frente a la opinión pública. 
Del precepto se extrae claramente que sujeto de imputación puede ser tanto la Administración Pública en general, como de hecho ocurre en el caso de la reclamación directa de responsabilidad patrimonial por el lesionado (art. 145.1 Ley 30/92), como el propio personal a su servicio, lo que se manifiesta en el ámbito sancionador o, como en el presente caso, como destinatario principal de la acción de regreso de la Administración.

Tradicionalmente, en nuestro Ordenamiento Jurídico esta acción de regreso o repetición (que claramente hunde sus raíces en la teoría civilista) se ha configurado de manera potestativa o facultativa en cuanto a su ejercicio, no siendo hasta la modificación de la Ley 30/92 por la Ley 4/1999, de 13 de enero, cuando se cambia esta tendencia y se consagra como una acción de obligado ejercicio por parte de la Administración.

De esta manera, textos normativos que han recogido la misma han sido la Ley de Régimen Local de $1950^{5}$, la Ley de Expropiación Forzosa de $1954^{6}$, su Reglamento de $1957^{7}$, pasando por la Ley de Régimen Jurídico de la Administración del Estado de $1957^{8}$.

La vigente Ley $7 / 1985$, de 2 de abril, reguladora de las Bases de Régimen Local sigue manteniendo un régimen potestativo en su art. 78.3, al establecer que (el subrayado es mío): "Las Corporaciones Locales podrán exigir la responsabilidad de sus miembros cuando por dolo o culpa grave hayan causado daños y perjuicios a la Corporación o a terceros, si éstos hubieses sido indemnizados por aquélla"'.

De igual manera lo configuró inicialmente la Ley $30 / 92$ en su redacción original del art. 145.210, pero ya en el marco del importante cambio que produjo esta Ley; esto es, la eliminación de la posibilidad de que el ciudadano pudiera exigir al empleado público responsabilidad civil directa por una lesión cometida por el mismo", debiendo dirigirse la acción de responsabilidad contra la Administración en general.

Comprobamos de esta manera cómo la Administración siempre respondería de las reclamaciones, lo que supone una garantía para el lesionado en particular, que asegura una indemnización y reparación íntegra por parte de la Administración, evitando posibles insolvencias del empleado público ${ }^{12}$.

Ahora bien, siendo ello una medida lógica y garantista, se observa una deficiencia en cuanto a la responsabilidad del propio sujeto que materialmente produce la lesión (autoridad o personal), pues configurándose como optativa la acción de regreso sólo respondería realmente si la misma llegara a ejercerse, por condena penal (art. 146 de la Ley 30/92), o en el concreto y específico supuesto de incurrir en responsabilidad contable ${ }^{13}$.

$5 \quad$ Art. 410.1: “La Corporación local podrá instruir expediente para la declaración de responsabilidad civil de sus autoridades, funcionarios y dependientes que por culpa o negligencia graves hubieren causado daños y perjuicios a la propia Corporación o a terceros, si éstos hubiesen sido indemnizados por aquélla".

6 Art. 121.1: "Dará también lugar a indemnización con arreglo al mismo procedimiento toda lesión que los particulares sufran en los bienes y derechos a que esta Ley se refiere, siempre que aquélla sea consecuencia del funcionamiento normal o anormal de los servicios públicos, o la adopción de medidas de carácter discrecional no fiscalizables en vía contenciosa, sin perjuicio de las responsabilidades que la Administración pueda exigir de sus funcionarios con tal motivo".

$7 \quad$ Art. 135: "Cuando los daños sean producidos por dolo o culpa grave del funcionario o funcionarios encargados del servicio, la Administración podrá repetir contra los mismos, cuando hubiere indemnizado directamente a los lesionados, sin perjuicio y con independencia de la responsabilidad penal en que hubieren podido incurrir los culpables.

Dicha responsabilidad se exigirá unilateralmente por la Administración a través del Ministro o de los Organismos competentes en las Corporaciones locales o Entidades institucionales, que harán la declaración de su derecho y su valoración económica, previo expediente, en el que deberá darse audiencia a los interesados y aportarse cuantas pruebas conduzcan a la ponderación de la responsabilidad del funcionario".

8 Art. 42.1: “... podrá la Administración exigir de sus autoridades, funcionarios o agentes la responsabilidad en que hubieren incurrido por culpa o negligencia graves, previa la instrucción del expediente oportuno con audiencia del interesado".

9 No obstante, a raíz de la nueva configuración obligatoria de la acción de manera general (como vemos a continuación en el texto principal), debe entenderse que este régimen potestativo en el ámbito local se ha tornado a su vez en preceptivo.

10 (Es subrayado es mío) "La Administración correspondiente, cuando hubiere indemnizado directamente a los lesionados, podrá exigir de sus autoridades y demás personal a su servicio la responsabilidad en que hubieran incurrido por dolo, culpa o negligencia grave, previa la instrucción del procedimiento que reglamentariamente se establezca".

11 Tal y como dispone el art. 145.1 de la Ley 30/92: "Para hacer efectiva la responsabilidad patrimonial a que se refiere el Capítulo I de este Título, los particulares exigirán directamente a la Administración Pública correspondiente las indemnizaciones por los daños y perjuicios causados por las autoridades y personal a su servicio".

De hecho, como refuerzo a esa nueva configuración de envío de las solicitudes de responsabilidad patrimonial hacia la Administración, se deroga también la vetusta Ley de 5 de abril de 1904, relativa a la responsabilidad de los funcionarios públicos, que contemplaba supuestos de exigencia de responsabilidad civil directa contra el personal administrativo.

12 A la vez que la Administración se asegura la unidad jurisdiccional del Orden Contencioso-Administrativo a estos efectos, que como en algún momento se ha señalado, puede llegar a ser más "benévola" para el sector público en la determinación del quantum indemnizatorio.

13 Arts. 38.1 de la Ley Orgánica del Tribunal de Cuentas 2/1982, de 12 de mayo, y 49 de la Ley de Funcionamiento del Tribunal de Cuentas de 7/1988, de 5 de abril; Art. 20.2 Real Decreto 429/1993, de 26 de marzo, por el que se aprueba el Reglamento de los Procedimientos de las Administraciones Públicas en materia de responsabilidad patrimonial. 
La conclusión era (y es) clara: Quienes verdaderamente responden son los contribuyentes, los ciudadanos en general que deben sufragar la indemnización al no repercutirse al autor material del daño ${ }^{14}$.

No obstante, la mencionada modificación efectuada por la Ley 4/1999, de 13 de enero, vino a suprimir el carácter voluntario o potestativo en el ejercicio de la acción, consagrando en el vigente art. 145 de la Ley 30/92 la obligatoriedad del ejercicio de la acción de regreso ${ }^{15}$.

Posteriormente comprobaremos si en verdad ello ha supuesto un verdadero cambio respecto a la situación anterior o ha sido una variación meramente cosmética.

En otro orden de cosas, la acción de regreso contemplada en el mencionado art. 145 de la Ley 30/92 $2^{16}$ contemplaría dos supuestos que, aunque íntimamente relacionados en el tratamiento, tienen un enfoque distinto en cuanto a su supuesto de hecho:

.- Art. 145.2: Acción de regreso de la Administración por daños producidos por sus autoridades y personal a bienes y derechos de particulares.

Se basa en una previa condena a la Administración al pago de una indemnización.

-- Art. 145.3: Acción directa de la Administración por los daños producidos por sus autoridades y personal respecto a bienes y derechos de la propia Administración.

En este caso, no se ha abierto ningún procedimiento administrativo todavía, por lo que deben confirmarse los requisitos generales de exigencia de responsabilidad (daño efectivo, evaluable económicamente, cuantía, etc...).

A pesar de estas diferencias, el tratamiento del segundo supuesto básicamente sigue idénticos cauces que el primero. Además, al estar tratando específicamente la acción de regreso fundada en una indemnización satisfecha a los lesionados, nos centraremos pues en el mencionado art. 145.2 de la Ley 30/92.

Debemos de esta manera realizar diversas precisiones en cuanto a la concreta operatividad de la acción de regreso ahora exigida a la Administración:

a).- Se obliga al inicio de un procedimiento de depuración de responsabilidades, no a la necesaria repercusión del montante indemnizado a la autoridad o personal implicados.

La acción se ejerce con este fin de acuerdo a unas breves líneas procedimentales establecidas en el art. 21 del Real Decreto 429/1993, de 26 de marzo, por el que se aprueba el Reglamento de los procedimientos de las Administraciones Públicas en materia de responsabilidad patrimonial ${ }^{17}$; y que recuerdan en gran medida a las fases seguidas en el procedimiento sancionador ${ }^{18}$.

14 Es por ello que lúcidamente GARCÍA DE ENTERRÍA y FERNÁNDEZ RODRÍGUEZ señalaban que: "Si las autoridades y funcionarios eran hasta 1992 prácticamente irresponsables de facto, tras la LPC pasaron a serlo prácticamente de iure, lo que resultaba notoriamente insano". GARCíA DE ENTERRÍA, Eduardo, FERNÁNDEZ RODRÍGUEZ, Tomás Ramón, Curso de Derecho Administrativo Il, p. 413, Civitas, Madrid, 2013.

15 Autores como MIR PUIGPELAT consideran que, una vez eliminada la posibilidad de acudir directamente contra la autoridad o personal por responsabilidad patrimonial, el no obligatoriedad en el ejercicio de la acción de regreso hubiera sido sencillamente escandalosa. MIR PUIGPELAT, Oriol, "Funcionaris responsables. La responsabilitat civil del personal al servei de I'Administració", Revista Jurídica de Catalunya, $n^{\circ}$ 4, Pp. 1033, 2002. Ahora bien, comprobaremos más adelante si, a efectos prácticos, ello supuso en verdad un cambio reseñable.

16 "1. Para hacer efectiva la responsabilidad patrimonial a que se refiere el Capítulo I de este Título, los particulares exigirán directamente a la Administración Pública correspondiente las indemnizaciones por los daños y perjuicios causados por las autoridades y personal a su servicio.

2. La Administración correspondiente, cuando hubiere indemnizado a los lesionados, exigirá de oficio de sus autoridades y demás personal a su servicio la responsabilidad en que hubieran incurrido por dolo, o culpa o negligencia graves, previa instrucción del procedimiento que reglamentariamente se establezca.

Para la exigencia de dicha responsabilidad se ponderarán, entre otros, los siguientes criterios: el resultado dañoso producido, la existencia o no de intencionalidad, la responsabilidad profesional del personal al servicio de las Administraciones públicas y su relación con la producción del resultado dañoso.

3. Asimismo, la Administración instruirá igual procedimiento a las autoridades y demás personal a su servicio por los daños y perjuicios causados en sus bienes o derechos cuando hubiera concurrido dolo, o culpa o negligencia graves.

4. La resolución declaratoria de responsabilidad pondrá fin a la vía administrativa.

5. Lo dispuesto en los párrafos anteriores, se entenderá sin perjuicio de pasar, si procede, el tanto de culpa a los Tribunales competentes".

17 El art. 19 de este Real Decreto viene a recordar lo que ya contempla el citado art. 145.2 de la Ley 30/92: "Satisfecha la indemnización, la Administración correspondiente podrá exigir de sus autoridades y demás personal a su servicio la responsabilidad en que hubieran incurrido por dolo, culpa o negligencia grave, previa la instrucción del procedimiento regulado en el artículo 21 de este Reglamento".

18 Regulado de manera general en el Real Decreto 1398/1993, de 4 de agosto, por el que se aprueba el Reglamento del procedimiento para el ejercicio de la Potestad Sancionadora. 
El procedimiento se inicia pues de oficio por el órgano competente, notificando el acuerdo de iniciación a los interesados donde se indicará los motivos y se otorgará un plazo de quince días para aportar cuantos documentos, informaciones y pruebas estimen precisos.

Una particularidad es que siempre deberá adjuntarse un informe del servicio administrativo donde se hubiera ocasionado la lesión.

Tras lo anterior, en igual plazo de quince días se procederá a la práctica de las pruebas admitidas.

Una vez practicada la prueba e inmediatamente antes de redactar la propuesta de resolución se pondrá lo instruido a conocimiento del interesado, concediéndole un plazo de diez días para formular las alegaciones que estime convenientes.

Tras el trámite de audiencia y en el plazo máximo de cinco días se formulará la propuesta de resolución, que será elevada al órgano competente para su resolución a su vez en el plazo máximo de cinco días.

La resolución pondrá fin a la vía administrativa (art. 145.4 de la Ley 30/92).

b).- La acción sólo prosperará si se dan unos requisitos legalmente determinados: Efectiva satisfacción previa de una indemnización al lesionado (1) - Dolo, culpa o negligencia graves (2).

Respecto al primer requisito parece obvio que es necesaria una indemnización efectivamente satisfecha con carácter previo para poder repercutir sobre su personal, que se habrá determinado tras el oportuno procedimiento administrativo o proceso contencioso-administrativo' 19.

El segundo requisito supone un auténtico privilegio respecto al régimen general civil de exigencia de responsabilidad a los particulares, ya que en el caso de autoridades y personal administrativo la culpabilidad está restringida a los supuestos más intensos.

Ello debe complementarse con lo siguiente.

c).- Para la exigencia de responsabilidad se deben ponderar diversos factores que pueden modular el quantum final exigible.

Tras comprobarse la existencia de una culpabilidad "cualificada" (dolo, culpa o negligencia de carácter grave), la responsabilidad a su vez podrá ser modulada en virtud del resultado dañoso producido, la existencia o no de intencionalidad, la responsabilidad profesional del autor del daño, y su grado de relación con la producción del daño.

Ello implica que, al contrario que la Administración, la cual está obligada a la reparación integral del daño, la cantidad concreta a reclamar por la misma a su personal puede llegar a ser inferior, lo que supone otro privilegio añadido.

A pesar de que se puede llegar a pensar que estas previsiones resultan injustificadas y establecen una gran diferencia respecto a los particulares, consideramos que tiene la lógica propia de las potestades administrativas, en el sentido de no paralizar la propia actividad administrativa y evitar que, por temor a la exigencia de responsabilidad ante cualquier tipo de error (incluso el más nimio), el personal al servicio de la Administración no ejecute determinadas acciones y medidas, adoptando una actitud excesivamente conservadora o temerosa que evite actuaciones que puedan llegar a ser necesarias.

A su vez, hay que tener en cuenta que las cuantías indemnizadas en el seno de la Administración pueden llegar a tener un montante muy elevado, por lo que resulta en principio también comprensible esos criterios de modulación de la cuantía, con el límite de la solvencia del empleado público.

19 Cabe decir que en los casos en los que la Administración tuviere contratado un seguro, siendo efectivamente la compañía aseguradora la que ha efectuado el pago de la indemnización, no cabrá la acción de regreso de la Administración ni la repetición de la empresa aseguradora, ya que se incurriría entonces en un enriquecimiento injusto. No obstante, como ya hemos señalado, todo ello sin perjuicio de que la Administración pueda exigir la responsabilidad disciplinaria correspondiente.

Vid. en este sentido, ABOGACÍA GENERAL DEL ESTADO, DIRECCIÓN DEL SERVICIO JURÍDICO DEL ESTADO, Manual de Responsabilidad Pública, p. 429, Aranzadi, Cizur Menor (Navarra), 2010; GAMERO CASADO, Eduardo, “Los contratos de seguro de responsabilidad extracontractual de las Administraciones Públicas”, Revista Española de Derecho Administrativo (REDA), n 103 , Pp. 357 y ss., 1999. 
Por otra parte y en relación también con estos criterios ponderativos, diversos autores ${ }^{20}$ consideran que los mismos actuarían en un estadio previo al ejercicio de la acción de regreso, teniendo por ello la Administración un amplio margen para considerar si finalmente ejerce o no ejerce la misma.

Particularmente, rechazamos esa interpretación de la norma, en torno a una especie de "ponderación previa" que matice la obligatoriedad meridiana que creemos el precepto establece.

De hecho, esos criterios ponderativos se aplican cuando ya se ha ejercido la acción e iniciado el procedimiento a que se refiere el párrafo primero.

Es decir, los criterios del párrafo segundo no pueden ser aplicados "ex ante" porque, precisamente, es en ese mismo procedimiento en el que se deberán dilucidar estos aspectos.

No tiene sentido alguno que la Administración ya prejuzgue estos criterios antes de ejercer la misma acción destinada a tal fin, amén de prescindir de un procedimiento para realizar esas ponderaciones, que permanecerían en el más estricto oscurantismo interno.

Cuestión distinta es que la Administración pueda realizar un período de información previa, a modo de "diligencias previas o preliminares", para sopesar la conveniencia o no del ejercicio de la acción, como bien dispone el art. 69.2 de la Ley $30 / 92$.

No obstante, al contrario que la potestad disciplinaria, por ejemplo, que permite un margen de apreciación y se ejerce de manera potestativa, no consideramos que este trámite tenga una especial utilidad en el seno de la acción que tratamos, pues precisamente el procedimiento administrativo previsto tiende a aclarar extremos dudosos, y la obligatoriedad de la acción de regreso nos hace decantarnos en contra de otorgar mayores márgenes de discrecionalidad a la Administración para su ejercicio ${ }^{21}$.

A su vez estamos ante supuestos de especial gravedad (que se habrán reflejado claramente en la cuantía indemnizatoria), por lo que el margen de dudas en cuanto a su iniciación es realmente escaso.

En definitiva, podríamos concluir que si bien la actual configuración del sistema de responsabilidad patrimonial resulta más práctica para el concreto lesionado, ya que acude directamente contra la Administración (solvente) para solicitar el resarcimiento de unos daños que le resultan imputables, también supone una especie de muro de contención o blindaje colectivo de su personal ${ }^{22}$, pues a pesar de que materialmente son los sujetos que han causado el daño (y no la Administración como ficción jurídica y centro de imputación), la pasividad en el ejercicio de la acción de regreso garantiza que al final sólo exista un único perjudicado: El contribuyente en general.

\section{3.- PROBLEMAS DERIVADOS DE LA ACTUAL CONFIGURACIÓN DE LA ACCIÓN}

\section{1.- Falta total de uso}

El calificativo "ignota" que intitula el artículo no se ha elegido como mero recurso estético, sino que en realidad prácticamente no contamos con datos de su ejercicio efectivo, tanto desde la época de su configuración facultativa como preceptiva.

A pesar de que las bases de datos jurisprudenciales están trufadas de Sentencias declarando la responsabilidad patrimonial de las Administraciones Públicas, mediando situaciones de dolo o imprudencia graves, existe una ausencia total de datos oficiales respecto al número de acciones o al ejercicio de la vía de regreso por la Administración.

20 DOMÉNECH PASCUAL, Gabriel, "Por qué la Administración nunca ejerce la acción de regreso contra el personal a su servicio", Indret: Revista para el Análisis del Derecho, n² 2, p. 8, 2008; MARTíN REBOLLO, Luís, "La acción de responsabilidad contra los profesionales sanitarios (Algunas reflexiones sobre la responsabilidad pública y la responsabilidad personal de los empleados públicos)”, Derecho y Salud, $\mathrm{n}^{\circ}$ 9-1, Pp. 9 y ss., 2001.

21 En apoyo de nuestra postura, la STSJ de Andalucía de 4 de enero de 2000 establece con claridad (el subrayado y paréntesis es mío): "si (la Administración), tras la instrucción del oportuno expediente, llega a tal conclusión (dolo, culpa o negligencia grave en la causación del daño) no puede dejar a su libre arbitrio la decisión de exigir o no la pertinente responsabilidad, sino que, en la medida en que es gestora de intereses públicos, viene obligada a su exigencia, en cuanto titular de ese derecho-deber legalmente atribuido y finalmente puesto claramente de manifiesto por la nueva redacción del repetido artículo 145.2 de la Ley 30/1992".

22 Especialmente contundente se muestra GONZÁLEZ PÉREZ, que señala como la actual configuración de la acción de regreso “supone prácticamente la absoluta impunidad de los funcionarios, y no digamos de los políticos".

Este autor incluso se muestra contrario a cualquier modulación de la responsabilidad de los empleados públicos: "Si incuestionable es el derecho de todo ciudadano a obtener plena reparación del daño sufrido como consecuencia de los servicios públicos, no menos lo es el derecho de todos a no soportar los gastos ocasionados por la soberbia, obcecación, cuando no negligencia y falta de preparación de los rectores de las Administraciones Públicas". GONZÁLEZ PÉREZ, Jesús, Responsabilidad Patrimonial de las Administraciones Públicas (7ª Ed.), Pp. 667 y 670 , Thomson-Civitas, Madrid, 2015. 
A su vez, la ínfima Jurisprudencia que se encuentra relativa a esta acción siempre viene referida al ámbito local, y respecto a cargos de tipo político como Alcaldes y Concejales.

Aunque tales tintes políticos pudieran hacer dudar de la legitimidad de este tipo de acciones, al fin y al cabo estos sujetos no dejan de desempeñar funciones públicas en tales momentos, por lo que es un supuesto viable ${ }^{23}$.

Se han intentado aportar diversas explicaciones de esta rotunda falta de ejercicio ${ }^{24}$ : Su coste político, las presiones y resistencias corporativas y sindicales, la concepción de "responsabilidad compartida" que subyace en la actuación pública, el desincentivo que supondría para la atracción de nuevo personal al empleo público, etc...; hasta la más simple y banal que se resume en la célebre frase "disparar con pólvora del Rey".

A su vez, se ha llegado a argumentar que también en el ámbito privado se produce un general desuso de esta acción de regreso por parte del empresario hacia el trabajador, por lo que no sería una particularidad exclusiva del ámbito público.

No obstante, frente a esto último se puede argumentar que en realidad sí existe esa repetición en el ámbito privado de manera común y habitual, aunque a menor escala, como son los casos de los conocidos descuadres en la "caja del día" en comercios, que se solucionan a través del denominado "complemento por quebranto de moneda".

Pero la verdadera razón por la que no se ejerce la vía de regreso a mayor escala en el ámbito privado es porque lo que se produce en cambio es el más contundente despido disciplinario. De esta manera, si bien no se repercute el coste del daño producido (dado que en muchas ocasiones puede aparecer la insolvencia del mismo), al trabajador se le "expulsa" de la relación laboral, en los supuestos amparados por la legislación social25.

En cambio, en el ámbito público no es sólo que no se ejerza la acción de regreso patrimonial, sino que ya resulta verdaderamente infrecuente la figura de la separación definitiva del servicio en el caso de los funcionarios de carrera, siendo a su vez especialmente cuidadoso el despido disciplinario del personal laboral ${ }^{26}$.

Sea como fuere, lo cierto es que la ausencia de ejercicio de la acción de regreso por la Administración da lugar a una consecuencia que ya hemos apuntado con anterioridad: La repercusión del pago indemnizatorio a los ciudadanos en general, con la consiguiente impunidad del autor real de la lesión.

A ello hay que añadir otro dato de suma importancia. Estamos frente a hechos en los que, como ha establecido la legislación, no son sólo meros deslices o errores que pueden cometerse en el ejercicio corriente de actividades, sino que estamos ante hechos en los que ha mediado dolo, culpa o negligencia graves.

Por lo tanto, desde el sujeto que voluntaria y conscientemente ha perpetrado un hecho lesivo desde el aparato administrativo (en dolo directo de primer grado), hasta casos de pura y llana incompetencia y desconocimiento profesional profundo, los mismos quedan impunes y absueltos de toda consecuencia, lo que tiene otra inmediata lectura: Los actores de hechos lesivos (algunos de ellos rozando el ámbito penal) siguen sin tener ningún desincentivo o estímulo para corregir su conducta en el futuro, permaneciendo en el aparato administrativo y restándole por consiguiente la necesaria eficiencia y eficacia, empeorando con todo ello el servicio público prestado.

Por último, llegamos a una situación paradójica, como es la mayor exigencia de responsabilidades en el ámbito privado que en el ámbito público, que teleológicamente se orienta a la satisfacción de los intereses generales como bien dispone el art. 103.1 de nuestra Constitución.

Desde el mencionado despido disciplinario hasta las especial fiscalización de los administradores empresariales en virtud de la legislación mercantil, simplemente no tiene justificación alguna la falta de ejercicio de la acción de regreso en el ámbito de la Administración Pública.

23 En la citada STSJ de Andalucía de 4 de enero de 2000 se establece (el paréntesis es mío): “... sin ánimo de prejuzgar, existen razones suficiente para al menos incoar el referido expediente (es decir, de ejercitar la acción de regreso) en depuración de la posible responsabilidad patrimonial del alcalde, máxime cuando media una petición expresa en tal sentido, sin que el hecho de haber efectuado a través de una moción del grupo socialista del Ayuntamiento legitime para presumir que existe trasfondo político y no un interés en la defensa de la legalidad, pues esa misma presunción podría atribuirse a la decisión del grupo de concejales que votaron en contra de dicha moción". También, vid. STSJ Comunidad Valenciana de 25 de julio de 2005 (Sala de lo Contencioso-Administrativo).

24 Una exposición de las principales causas podemos encontrarlas en DOMÉNECH PASCUAL, Gabriel, “Por qué la Administración nunca ejerce....", Pp. 8-14.

25 Arts. 55 y 55 del Real Decreto Legislativo 1/1995, de 24 de marzo, por el que se aprueba el Texto Refundido de la Ley del Estatuto de los Trabajadores.

26 A ello se le unen diversos casos de despido disciplinario intentados en fraude de Ley, donde la Jurisdicción Contencioso-Administrativa ha obligado a la readmisión. Vid. STS de 4 de noviembre de 2010 (Sala de lo Social), i.e. 


\section{2.- Problemas de legitimación para su ejercicio}

El principal problema ante la pasividad o resistencia de la Administración al ejercicio de la acción de regreso es precisamente que no existen medios adecuados para conseguir su ejercicio forzoso $\mathrm{O}^{27}$; porque no olvidemos que estamos ante una expresa obligación legal, no siendo el ejercicio de la acción de regreso una mera facultad u opción de la Administración, que no puede valorar si ejercerla o no ejercerla. Cuestión distinta es que deba efectivamente repercutir la cuantía satisfecha en concepto de indemnización a la autoridad o personal, lo cual se deliberará en el procedimiento al efecto.

En la actualidad contaríamos con varias vías al efecto, que adolecen sin embargo de debilidad o son marginales en cuanto a su empleo:

En primer lugar, una posibilidad para instar que la Administración ejercite la acción de regreso es la solicitud por parte del ciudadano de inicio del procedimiento administrativo de oficio a través de denuncia (art. 69.1 de la Ley 30/92).

Este tipo de acción instada por el particular no iría dirigida a resarcir ninguna lesión (que se exige por otros cauces), sino a restaurar el buen funcionamiento de la Administración y la rendición de cuentas, en aras de evitar que una conducta negligente permanezca impune en el aparato administrativo. En definitiva, velar por los intereses generales ${ }^{28}$. En estos casos, a diferencia del ámbito de la potestad sancionadora y disciplinaria, donde la propuesta de inicio procedimental se refiere a una potestad pública que queda en el ámbito de la autonomía administrativa ${ }^{29}$, la exigencia de la vía de regreso se fundamenta en un mandato legalmente exigido, y cuya inobservancia se traduce en una perjuicio general a la Hacienda Pública. En definitiva, se estaría solicitando un estricto control de legalidad, no de oportunidad.

Ahora bien, el principal problema que enfrentamos en esta vía es la calificación de la denuncia como mero interés simple, que sólo permitiría al particular sugerir a la Administración el inicio del procedimiento oportuno, pero nada más ${ }^{30}$.

No obstante, al contrario de lo que acabamos de precisar respecto al ámbito sancionador, consideramos que en el caso de la acción de regreso en el ámbito de la responsabilidad patrimonial, debido al cristalino mandato legal y al interés general subyacente claramente damnificado, bien podría dar lugar a calificar el mismo como un interés cualificado ${ }^{31}$.

Si bien no para producir una personación en el procedimiento, que necesariamente debe ser instruido y resuelto de oficio por la Administración, sí como derecho reaccional que permita instar el oportuno recurso contencioso-administrativo, ante un pronunciamiento expreso denegatorio del inicio del procedimiento o ante la inactividad administrativa formal.

27 BARCELONA LLOP, Javier, “La acción de regreso en la Ley de Régimen Jurídico de las Administraciones Públicas y del Procedimiento Administrativo Común”, Revista Española de Derecho Administrativo (REDA), n 105, Pp. 44 y ss., 2000.

28 Como acertadamente reflexiona BLANQUER CRIADO: "Con el transcurso del tiempo, el régimen de responsabilidad se ha construido desde la perspectiva del perjudicado (de donde resulta el carácter objetivo y directo de la responsabilidad), prescindiendo de la perspectiva indeclinable del Derecho Público (que es la satisfacción de los intereses generales). En esa situación, el carácter objetivo de la responsabilidad de una persona ficticia (la Administración), termina funcionando como una cláusula de exoneración de la responsabilidad subjetiva de las personas físicas a las que rasgando el velo puede y debe imputarse la responsabilidad". BLANQUER CRIADO, David, La responsabilidad patrimonial de las Administraciones Públicas. Ponencia especial de estudios del Consejo de Estado, Pp. 112-113, Ministerio de Administraciones Públicas, Madrid, 1997.

29 Es por este motivo que, en estos casos, aun admitiéndose el inicio del procedimiento sancionador de oficio a través de denuncia (art. 11.1 d) del RD 1398/1993), la propia normativa expresa que la misma no vincula al órgano competente para iniciar el procedimiento (art. 11.2), matizando la Jurisprudencia que el particular en estos casos carece de una legitimación más allá del mero interés simple, lo que no le faculta para ser parte en el proceso. Entre otras, vid. SsTS (Sala de lo Contencioso-Administrativo) de 3 de febrero de 1982 ; de 12 de marzo de 1991; de 9 de diciembre de 1999.

30 Tal y como señala la STSJ de Asturias de 17 de enero de 2002: “... el fundamento de la denuncia puede buscarse en el artículo 23.1 de la Constitución, referente al derecho constitucional de participación del administrado en la Administración, lo que supone ha de calificarse como acción, ya que es actuación de un derecho por el particular, pero sin el contenido que la palabra acción podría conllevar, porque el procedimiento que se origina no tiene el carácter de proceso entre partes, ni se atiene al principio de contradicción".

31 Nos resguardamos deliberadamente de utilizar el término "interés legítimo" por cuanto la Jurisprudencia (a pesar de su tendencia a la interpretación "pro actione") se ha mostrado restrictiva a la hora de reconocer un "interés legítimo general”, por referencia al genérico cumplimiento de la legalidad. Tal y como ha sostenido el Tribunal Supremo (entre otras, STS de 26 de junio de 1997), el reconocimiento de interés legítimo debe ir referido a una especial relación del sujeto con el objeto del proceso, del que pueda derivar un directo efecto positivo (beneficio) o negativo (perjuicio) para el mismo.

De esta manera, la STS de 12 de julio de 2005 establece: “... el concepto de interés legítimo no puede ser asimilado al de interés en la legalidad, que haría equiparable la legitimación en el orden jurisdiccional contencioso-administrativo a la legitimación popular, que sólo en los casos expresamente contemplados en la Ley es admisible".

Del mismo modo, no se puede argüir como beneficio directo "una recompensa de orden moral o el beneficio de carácter cívico o de otra índole que lleva aparejado el cumplimiento de la legalidad” (SsTS de 18 de enero de 2005; de 25 de septiembre de 2009 ; de 20 de enero de 2012). 
En cuanto a la operatividad del silencio administrativo en estos casos surgen a su vez diversas dudas, en cuanto a si resultaría aplicable no ya a un procedimiento administrativo principal, sino a esta fase previa de solicitud de inicio por denuncia. Y, más importante aún, qué valor concreto tendría el silencio administrativo de llegar operar (negativo ó caducidad del procedimiento), pues depende de la óptica que se escoja la resolución puede ser considerada favorable o desfavorable. Cuestión nada sencilla de dilucidar.

A su vez, la vía de la impugnación judicial ex art. 29 de la LJCA 29/1998 parece que, en principio, también se encuentra vedada, pues se limitaría a una inactividad material de la Administración, y no propiamente a la inactividad de tipo formal ${ }^{32}$.

Por lo tanto, por inactividad de este tipo debería acudirse al contencioso por los cauces ordinarios de recurso (art. 25.2 LJCA 29/1998).

No obstante lo dicho, si a pesar de todo lo anterior se llegara a sede jurisdiccional, el órgano judicial no podría pronunciarse hasta que se hubiera efectuado el procedimiento de regreso, para lo cual exigiría el inicio del procedimiento obligatorio del art. 21 del RD 429/93 33; y en el caso de que ya se hubiera tramitado ese procedimiento (supuesto de laboratorio con los actuales datos), el órgano judicial ya podría ejercer con normalidad su función revisora.

Expuesto todo lo anterior, y por si no hubiera suficientes complicaciones, el mecanismo de la denuncia del particular tiene otra añadida en el supuesto de que se consiguiera un pronunciamiento de la Administración: La determinación de si en un concreto supuesto existe dolo, culpa o negligencia grave depende prácticamente de la propia Administración, en cuyo caso el ente administrativo en cuestión podría despachar la solicitud de inicio de oficio por denuncia señalando que simplemente no concurren los mismos, y sin siquiera iniciar el procedimiento tendente a dilucidar si efectivamente se produjo esa culpabilidad y, en ese caso, exigir responsabilidad a la autoridad o personal.

Recordemos que, según sostuvimos, la ponderación y valoración del dolo, imprudencia o negligencia graves y, más aún, las circunstancias moduladoras de la responsabilidad, no deben valorarse con carácter previo al procedimiento propio de la acción de regreso.

En segundo lugar, el ámbito local ofrece quizás una vía “más clara” para instar a la Administración al ejercicio de la acción de regreso, aunque lógicamente con un ámbito de actuación limitado al territorio de la Entidad Local en cuestión. Sería la conocida "acción vecinal" recogida en el art. 68 de la LBRL $7 / 85$ 34. Si bien el vecino no podría lógicamente iniciar el procedimiento, sí estaría habilitado para acudir a la vía Contencioso-Administrativa para solicitar del órgano jurisdiccional que exhorte a la Administración a su ejercicio, o a la revisión del acto en el caso de que se hubiera tramitado el procedimiento de regreso.

Ahora bien, tengamos en cuenta que, procesalmente, la acción vecinal atendería a la naturaleza de acción subrogatoria o sustitutoria de la iniciativa local, pero no constituiría propiamente una acción pública o popular, donde el ciudadano pueda acudir directamente y formular una pretensión que se base en la vulneración de la legalidad por el propio Ente Local.

En tercer lugar, la vía del Defensor del Pueblo y las Defensorías autonómicas. En el ámbito estatal, el art. 26 de la LO 3/1981, de 6 de abril, del Defensor del Pueblo, habilita a este órgano de relevancia constitucional para emprender la denominada "acción de responsabilidad" contra autoridades, funcionarios y agentes civiles del orden gubernativo o administrativo, que sin dudas abarcaría el aviso para el ejercicio de la acción de regreso. No obstante, por razones obvias de medios materiales este sendero es por naturaleza secundario o residual.

Y, en cuarto lugar, la vía del Consejo de Estado, todavía más residual que la anterior.

El art. 130.4 del Real Decreto 1674/1980, de 18 de julio, por el que se aprueba el Reglamento Orgánico del Consejo de Estado contempla la posibilidad de que, en forma separada del cuerpo del Dictamen, se pueda añadir la

\footnotetext{
32 GÓMEZ PUENTE, Marcos, La inactividad de la Administración, p. 527, Aranzadi, Pamplona, 2011.

33 Así se preveía en el párrafo extractado de la citada STSJ de Andalucía de 4 de enero de 2000.

34 “1. Las entidades locales tienen la obligación de ejercer las acciones necesarias para la defensa de sus bienes y derechos.

2. Cualquier vecino que se hallare en pleno goce de sus derechos civiles y políticos podrá requerir su ejercicio a la Entidad interesada. Este requerimiento, del que se dará conocimiento a quienes pudiesen resultar afectados por las correspondientes acciones, suspenderá el plazo para el ejercicio de las mismas por un término de treinta días hábiles.

3. Si en el plazo de esos treinta días la entidad no acordara el ejercicio de las acciones solicitadas, los vecinos podrán ejercitar dicha acción en nombre e interés de la entidad local.

4. De prosperar la acción, el actor tendrá derecho a ser reembolsado por la Entidad de las costas procesales y a la indemnización de cuantos daños y perjuicios se le hubieran seguido".
} 
denominada "acordada", que incoará el expediente de responsabilidad por culpa contra algún funcionario cuando lo estime necesario. Esta "acordada" no se publicará, dictándose la resolución mediante acuerdo u oído el Consejo de Estado.

\section{3.- Procedimiento insuficiente formulado para el ejercicio de la concreta acción}

Junto al anteriormente mencionado problema de legitimación, debemos añadirle que el procedimiento para ejercer la acción de regreso, contemplado en el RD 429/1993, tiene multitud de lagunas en sí mismo35.

El art. 21 del RD 429/93 hace referencia al “órgano competente”, pero ¿cuál es el mismo? ¿Cuál es el instructor que inicia el procedimiento y cuál el resolutorio que lo finaliza?.

Parece lógico pensar que la unidad administrativa que ha debido indemnizar sea la que instruya el expediente, siendo los máximos órganos en donde se incardine los competentes para resolver, como es el caso del Ministro en sede estatal, el Director-Presidente para los entes instrumentales o institucionales, el Consejero en las Comunidades Autónomas, y el Pleno en las Entidades Locales.

Por otra parte, ¿cuál es el plazo concreto para ejercitar la acción de repetición y cómo se computa tal plazo? Si bien parece claro que el pago de la indemnización es un paso previo, ¿es necesario que un eventual recurso judicial adquiera firmeza para el comienzo de tal plazo o es suficiente con que efectivamente la Administración ya haya procedido al pago del montante indemnizatorio? ${ }^{36}$.

A su vez, no queda claro el íter temporal entre la fase de alegaciones y la de audiencia, esta última como se sabe fundamental ex art. 105 c) de la Constitución Española. De hecho, de la dicción literal del art. 21 del RD $429 / 93$ pareciera que la fase de alegaciones resulta más importante que la propia audiencia al interesado, a la vez que guarda silencio del momento concreto en que debe producirse.

También guarda silencio la regulación a la hora de determinar el tipo de responsabilidad que se establece en el caso más que probable de que hubiesen varios sujetos causantes del daño: Mancomunada, solidaria, etc...

Además, como ha sido puesto de manifiesto, existe una falta de previsión respecto a la coordinación de esta acción de regreso con las acciones referidas a la responsabilidad disciplinaria ${ }^{37}$, que pueden venir íntimamente relacionadas, y que sería conveniente contemplar en aras de la economía procesal.

En definitiva, nada de lo anterior queda claro, lo que no supone en absoluto una cuestión baladí.

\section{4.- LA ACCIÓN DE REGRESO EN LOS PROYECTOS DE LEY DE RÉGIMEN JURÍDICO DEL SECTOR PÚBLICO Y DE LEY DE PROCEDIMIENTO ADMINISTRATIVO COMÚN DE LAS ADMINISTRACIONES PÚBLICAS}

Visto en las páginas principales el complicado estado de la cuestión, debemos detenernos en los recientes Proyectos de Ley ${ }^{38}$ que, de aprobarse definitivamente, quizás puedan arrojar algo de luz y, sobretodo, utilidad práctica a la acción de regreso de la Administración.

- En primer lugar, tratando el Proyecto de Ley de Régimen Jurídico del Sector Público, encontramos en su art. 36 la nueva ubicación del tema que tratamos, bajo el título de "exigencia de la responsabilidad patrimonial de las autoridades y personal al servicio de las Administraciones Públicas”.

35 Señalando algunas de las deficiencias procedimentales que señalamos, GALLARDO CASTILLO concluye que "pareciera que el legislador ha diseñado un producto para que no sea usado. O para que lo sea a discreción”. GALLARDO CASTILLO, María Jesús, Régimen Jurídico de las Administraciones Públicas y Procedimiento Administrativo Común. Comentario sistemático a la Ley 30/1992, de 26 de noviembre, Pp. 742-743, Tecnos, Madrid, 2010.

36 En una de las pocas y aisladas Sentencias que hemos encontrado al respecto, concretamente en la STSJ de Castilla y León de 13 de diciembre de 1999 (Sala de lo Contencioso), el Tribunal considera a este respecto: "Si bien no se hace una referencia expresa al plazo que el Reglamento denomina de "prescripción”, de un año, según el art. 4, esta Sala entiende que debe aplicarse a este procedimiento de "repetición". En efecto, si la Administración no responde cuando el particular tarda más de un año en ejercitar la acción de responsabilidad, es lógico entender que debe a su vez repetir contra el funcionario por la citada responsabilidad en el mismo plazo. Y si para la Administración el plazo (en el supuesto en que se derive de una sentencia) de responsabilidad se cuenta desde la fecha de firmeza de la sentencia en cuestión, el mismo "diez a quo" debe tenerse en cuenta para contar el plazo a los efectos de repetir contra el funcionario".

37 GARCÍA ÁLVAREZ, Gerardo, "La responsabilidad patrimonial de autoridades y personal al servicio de las Administraciones Públicas", en QUINTANA LÓPEZ, Tomas (Dir.), CASARES MARCOS, ANA BELÉN, La responsabilidad patrimonial de la Administración Pública, Tomo I (2 ${ }^{a}$ Ed.), p. 625, Tirant Lo Blanch, Valencia, 2013.

38 Ambos Proyectos de Ley resultan accesibles a través de los siguientes enlaces: Proyecto de Ley de Régimen Jurídico del Sector Público 121/000154, 18 de mayo de 2015: http://www.congreso.es/public_oficiales/L10/CONG/BOCG/A/BOCG-10-A-154-1.PDF; Proyecto de Ley del Procedimiento Administrativo Común de las Administraciones Públicas 121/000155, 18 de mayo de 2015: http://www.congreso.es/public_oficiales/L10/CONG/BOCG/A/BOCG-10-A-155-1.PDF 
Tal artículo dispone:

"1. Para hacer efectiva la responsabilidad patrimonial a que se refiere esta Ley, los particulares exigirán directamente a la Administración Pública correspondiente las indemnizaciones por los daños y perjuicios causados por las autoridades y personal a su servicio.

2. La Administración correspondiente, cuando hubiere indemnizado a los lesionados, exigirá de oficio en vía administrativa de sus autoridades y demás personal a su servicio la responsabilidad en que hubieran incurrido por dolo, o culpa o negligencia graves, previa instrucción del correspondiente procedimiento. Para la exigencia de dicha responsabilidad y, en su caso, para su cuantificación, se ponderarán, entre otros, los siguientes criterios: el resultado dañoso producido, el grado de culpabilidad, la responsabilidad profesional del personal al servicio de las Administraciones públicas y su relación con la producción del resultado dañoso.

3. Asimismo, la Administración instruirá igual procedimiento a las autoridades y demás personal a su servicio por los daños y perjuicios causados en sus bienes o derechos cuando hubiera concurrido dolo, $o$ culpa o negligencia graves.

4. El procedimiento para la exigencia de la responsabilidad al que se refieren los apartados 2 y 3 , se sustanciará conforme a lo dispuesto en la Ley de procedimiento administrativo común de las Administraciones Públicas y se iniciará por acuerdo del órgano competente que se notificará a los interesados y que constará, al menos, de los siguientes trámites:

a) Alegaciones durante un plazo de quince días.

b) Práctica de las pruebas admitidas y cualesquiera otras que el órgano competente estime oportunas durante un plazo de quince días.

c) Audiencia durante un plazo de diez días.

d) Formulación de la propuesta de resolución en un plazo de cinco días a contar desde la finalización del trámite de audiencia.

e) Resolución por el órgano competente en el plazo de cinco días.

5. La resolución declaratoria de responsabilidad pondrá fin a la vía administrativa.

6. Lo dispuesto en los apartados anteriores, se entenderá sin perjuicio de pasar, si procede, el tanto de culpa a los Tribunales competentes."

Observamos como en el apartado cuarto del artículo se contiene en gran medida el procedimiento de ejercicio de la acción de repetición contemplado en el RD 429/1993; a su vez el propio artículo 36 se remite al procedimiento general de la Ley de Procedimiento Administrativo Común, y no a ninguna norma reglamentaria como hace nuestra actual Ley $30 / 92^{39}$. gativa.

Respecto a este apartado cuarto debemos realizar un par de matizaciones al efecto, una positiva y otra ne-

En cuanto a la positiva, se aclara y se plasma más nítidamente el íter procesal de la acción, ya que donde antes se confundía trámite de alegaciones y audiencia, en el presente artículo queda despejado cómo se sucede cada fase, lo que siempre es útil.

39 Es por ello que el citado RD 429/1993 quedaría, en este concreto aspecto, efectivamente desplazado por la nueva previsión normativa del proyecto de Ley de Régimen Jurídico. 
Ahora bien, debemos resaltar cómo de entre los trámites establecidos en el procedimiento, no se hace mención alguna al Informe emitido por el servicio donde se haya ocasionado la lesión indemnizable, por lo que se puede entender que ya no resulta un trámite exigible.

En cuanto a la negativa, se sigue sin indicar ni establecer reglas en cuánto a qué órgano se considera competente para iniciar la acción, instruir y proponer la resolución, y cuál para definitivamente resolver.

De esta manera, no se aportan criterios para distinguir entre el órgano instructor y el órgano resolutorio, lo que no supone una cuestión menor en estos asuntos tan delicados.

A su vez, nada se dice respecto a la coordinación con el ejercicio de acciones disciplinarias, sucesivas o acumuladas.

- Por lo que se refiere al Proyecto Ley de Procedimiento Administrativo Común de las Administraciones Públicas, debemos destacar especialmente el art. 62, donde se detalla el inicio del procedimiento por denuncia, al estilo de lo que desarrolla el art. 11 del RD 1398/1993 en el ámbito del procedimiento sancionador.

Esto supone dotar de un mayor contenido a lo que el actual art. 69.1 de la Ley 30/92 sólo menciona brevemente como una posibilidad, sin explicar exactamente su funcionamiento y efectos.

De este modo, el art. 62 del proyecto dispone:

"1. Se entiende por denuncia, el acto por el que cualquier persona, en cumplimiento o no de una obligación legal, pone en conocimiento de un órgano administrativo la existencia de un determinado hecho que pudiera justificar la iniciación de oficio de un procedimiento administrativo.

2. Las denuncias deberán expresar la identidad de la persona o personas que las presentan y el relato de los hechos que se ponen en conocimiento de la Administración. Cuando dichos hechos pudieran constituir una infracción administrativa, recogerán la fecha de su comisión y, cuando sea posible, la identificación de los presuntos responsables.

3. Cuando la denuncia invocara un perjuicio en el patrimonio de las Administraciones Públicas la no iniciación del procedimiento deberá ser motivada y se notificará a los denunciantes la decisión de si se ha iniciado o no el procedimiento. En todo caso, cuando el denunciante haya participado en la comisión de una infracción de esta naturaleza y existan otros infractores, el órgano competente para resolver el procedimiento deberá eximir al denunciante del pago de la multa que le correspondería u otro tipo de sanción de carácter no pecuniario, cuando sea el primero en aportar elementos de prueba que permitan iniciar el procedimiento o comprobar la infracción, siempre y cuando en el momento de aportarse aquellos no se disponga de elementos suficientes para ordenar la misma y se repare el perjuicio causado. Asimismo, el órgano competente para resolver deberá reducir el importe del pago de la multa que le correspondería o, en su caso, la sanción de carácter no pecuniario, cuando no cumpliéndose alguna de las condiciones anteriores, el denunciante facilite elementos de prueba que aporten un valor añadido significativo respecto de aquellos de los que se disponga. En ambos casos será necesario que el denunciante cese en la participación de la infracción y no haya destruido elementos de prueba relacionados con el objeto de la denuncia.

4. La presentación de una denuncia no confiere, por sí sola, la condición de interesado en el procedimiento."

La importancia de citar este artículo en concreto trae causa de lo que anteriormente expusimos, cual es la importante posibilidad de que el ciudadano pueda exigir a la Administración el ejercicio de la acción de regreso, ya que, como venimos repitiendo e insistiendo en el presente trabajo, la inactividad se traduce en un incumplimiento de un meridiano mandato legal obligatorio para la Administración.

A pesar de ello, el apartado cuarto de este artículo nos recuerda que la denuncia, por sí sola, no atribuye la condición de interesado en el procedimiento.

En definitiva, podríamos concluir que los Proyectos de Ley aportan poco desde el punto de vista de dotar de una mayor efectividad o virtualidad práctica a la acción de regreso, ya que si se pierde la batalla de dotar una legitimidad más amplia a la ciudadanía para que pueda combatir la pasividad manifiesta de la Administración en el 
cumplimiento de esta obligación, seguimos quedándonos con un instrumento estéril en el Ordenamiento Jurídico; instrumento que de ser empleado cambiaría profundamente el actuar administrativo.

\section{5.- PROPUESTAS Y CONCLUSIÓN}

A la vista de los acontecimientos podríamos plantear varios tipos de propuestas, que podríamos denominar como la "realista", la "pragmática", y la "reformadora".

.- La realista, al observar lo desarrollado y sin caer en cierto ánimo de resignación, es directamente la eliminación la acción, ante el flagrante y notorio incumplimiento de su mandato legal.

Por la vía de los hechos se ha comprobado como estamos ante una mera acción cosmética, y en cierta medida grosera para la ciudadanía, por cuanto al haber eliminado la posibilidad del ejercicio de la acción de responsabilidad civil directa contra autoridades y personal al servicio de las Administraciones Públicas, se blinda totalmente la impunidad de ciertos hechos y se consagra el perjuicio general para la Hacienda Pública.

De esta manera una supresión de la misma, siendo políticamente indeseada (pues actúa como un placebo social totalmente inocuo $)^{40}$, sería infinitamente más sincera para con la ciudadanía, evitándose juegos de artificio legales que sólo aportan una esperanza ilusoria.

-- La pragmática consistiría en, sin excesivos cambios legislativos, configurar vías que garanticen su efectividad, para no cejar en el empeño de conservar una acción que, bien ejercida, consideramos una vía fundamental para garantizar una Administración moderna y, sobretodo, justa.

Para ello, se debe reconocer claramente al ciudadano su interés para que se cumpla la legalidad en este asunto, permitiéndole acudir a la vía contenciosa en caso de pronunciamiento expreso denegatorio, silencio administrativo e inactividad de la Adm.

En este sentido, se podría seguir desde la vía de una simple adición al articulado, al estilo de la $L B R L 7 / 85^{41}$, o la configuración de una auténtica y más clara acción popular, como la establecida en el ámbito del urbanismo ${ }^{42}$ o en materia de responsabilidad contable ${ }^{43}$.

Cabe reflexionar que esta "habilitación ciudadana" para iniciar una exigencia responsabilidades a los entes públicos, lejos de una moda del actual contexto al que nos hemos referido, viene siendo una preocupación constante que no cesa desde los orígenes del Estado Liberal44.

-- La reformadora iría más allá de las modificaciones anteriormente efectuadas, estableciendo una serie de medidas de amplio espectro.

En este sentido se ha argumentado que podría otorgarse legitimación al Ministerio Fiscal para el ejercicio de la acción de regreso ${ }^{45}$; establecer un sistema de sanciones respecto a las autoridades y órganos superiores que no ejercieran la obligada acción de regreso; constituir una Agencia independiente para ejercer labores de instrucción en casos de regreso o directamente atribuir a la Jurisdicción Contencioso-Administrativa la exigencia de este tipo de responsabilidades patrimoniales ${ }^{46}$.

No obstante, este último aspecto es ciertamente más problemático si tenemos en cuenta nuestra tradición jurisdiccional y el carácter revisor de las Jurisdicción Contencioso-Administrativa.

40 Por ello, autores como DíEZ SÁNCHEZ han calificado a la acción de regreso como un "bonito florero" puesto para tranquilizar conciencias. DÍEZ SÁNCHEZ, Juan José, “Las acciones de regreso contra autoridades y funcionarios públicos”, en MORENO MARTíNEZ, Juan Antonio (Coord.), La responsabilidad civil y su problemática actual, Pp. 215-216, Dykinson, Madrid, 2007.

41 El art. 63.1b) de la LBRL 7/85 otorga legitimación expresa a los miembros de las corporaciones que hubieran votado en contra de los actos y acuerdos acordados en su seno y que incurran en una infracción del Ordenamiento Jurídico.

Si bien observamos que es una legitimación básicamente referida al ámbito del Pleno y el órgano de gobierno municipal, nada impediría aplicar este tipo de fórmula a una escala mayor, referida a la inactividad de la Administración en el ejercicio de la acción de regreso.

42 Art. 48. Del Real Decreto Legislativo 2/2008, de 20 de junio, por el que se aprueba el Texto Refundido de la Ley del Suelo.

43 Arts. 47.3 de la LO 2/1982, del Tribunal de Cuentas; y 56 de la Ley 7/1988, de Funcionamiento del Tribunal de Cuentas.

44 De este modo, el art. 15 de la Declaración de los Derechos del Hombre y del Ciudadano de 1789 ya establecía solemnemente: “La Sociedad tiene derecho a pedir a todo agente público cuentas de su administración" ("La société a le droit de demander compte à tout agent public de son administration").

45 Se basaría en la base constitucional del art. 124.1, que dispone: "El Ministerio Fiscal, sin perjuicio de las funciones encomendadas a otros órganos, tiene por misión promover la acción de la justicia en defensa de la legalidad, de los derechos de los ciudadanos y del interés público tutelado por la ley, de oficio o a petición de los interesados, así como velar por la independencia de los Tribunales y procurar ante éstos la satisfacción del interés social".

A favor de esta medida se muestra BARCELONA LLOP, Javier, “La acción de regreso ... ”, Pp. 48-49.

46 BLANQUER CRIADO, David, La responsabilidad patrimonial de las Administraciones Públicas, Pp. 117-119. 
Terminamos este estudio regresando a la reflexión inicial. En una época donde la transparencia, la eficiencia y la responsabilidad adquieren carta de naturaleza en todos los planos (político, jurídico, social), dejar en el limbo un mecanismo como la acción de regreso de la Administración respecto a sus autoridades y personal contribuye decisivamente al aumento de la sensación de impunidad pública, de desconfianza ciudadana, y de desapego y desdén hacia la Administración; y, en definitiva, hacia las Instituciones y "lo público" en general, lo que se traduce en una falta de legitimidad que, sencillamente, ya no podemos permitir en el mencionado contexto.

Creemos que una seria reflexión respecto a todo lo expuesto de cara a futuras reformas normativas, cuando menos, merece el esfuerzo.

\section{BIBLIOGRAFÍA}

- ABOGACÍA GENERAL DEL ESTADO, DIRECCIÓN DEL SERVICIO JURÍDICO DEL ESTADO, Manual de Responsabilidad Pública, Aranzadi, Cizur Menor (Navarra), 2010.

- BARCELONA LLOP, Javier, "La acción de regreso en la Ley de Régimen Jurídico de las Administraciones Públicas y del Procedimiento Administrativo Común”, Revista Española de Derecho Administrativo (REDA), n 105, 2000.

- BLANQUER CRIADO, David, La responsabilidad patrimonial de las Administraciones Públicas. Ponencia especial de estudios del Consejo de Estado, Ministerio de Administraciones Públicas, Madrid, 1997.

- DÍEZ SÁNCHEZ, Juan José, “Las acciones de regreso contra autoridades y funcionarios públicos”, en MORENO MARTíNEZ, Juan Antonio (Coord.), La responsabilidad civil y su problemática actual, Dykinson, Madrid, 2007.

- DOMÉNECH PASCUAL, Gabriel, “Por qué la Administración nunca ejerce la acción de regreso contra el personal a su servicio”, Indret: Revista para el Análisis del Derecho, $\mathrm{n}^{\circ}$ 2, 2008.

- GALLARDO CASTILLO, María Jesús, Régimen Jurídico de las Administraciones Públicas y Procedimiento Administrativo Común. Comentario sistemático a la Ley 30/1992, de 26 de noviembre, Tecnos, Madrid, 2010.

- GAMERO CASADO, Eduardo, “Los contratos de seguro de responsabilidad extracontractual de las Administraciones Públicas", Revista Española de Derecho Administrativo (REDA), n 103, 1999.

- GARCÍA ÁLVAREZ, Gerardo, “La responsabilidad patrimonial de autoridades y personal al servicio de las Administraciones Públicas”, en QUINTANA LÓPEZ, Tomas (Dir.), CASARES MARCOS, ANA BELÉN, La responsabilidad patrimonial de la Administración Pública, Tomo I (2 ${ }^{a}$ Ed.), Tirant Lo Blanch, Valencia, 2013.

- GARCÍA DE ENTERRÍA, Eduardo, FERNÁNDEZ RODRÍGUEZ, Tomás Ramón, Curso de Derecho Administrativo II, Civitas, Madrid, 2013.

- GÓMEZ PUENTE, Marcos, La inactividad de la Administración, Aranzadi, Pamplona, 2011.

- GONZÁLEZ PÉREZ, Jesús, Responsabilidad Patrimonial de las Administraciones Públicas (7ª Ed.), Thomson-Civitas, Madrid, 2015.

- MARTíN REBOLLO, Luís, “La acción de responsabilidad contra los profesionales sanitarios (Algunas reflexiones sobre la responsabilidad pública y la responsabilidad personal de los empleados públicos)”, Derecho y Salud, n 9-1, 2001.

- MIR PUIGPELAT, Oriol, “Funcionaris responsables. La responsabilitat civil del personal al servei de I'Administració”, Revista Jurídica de Catalunya, $\mathrm{n}^{\circ}$ 4, 2002

- SAURA FRUCTUOSO, Carlos, “El derecho de buena administración y el “due process" administrativo europeo”, en Procedimiento Administrativo Europeo, Civitas, Madrid, 2012. 